\title{
Acupuncture Therapy
}

National Cancer Institute

\section{Source}

National Cancer Institute. Acupuncture Therapy. NCI Thesaurus. Code C15176.

The practice of piercing specific points on the body with very thin sterile needles in order to relieve pain or induce regional anesthesia. 